\section{Local Exhaust Ventilation to Control Dental Aerosols and Droplets}

\author{
J.R. Allison ',2 $\mathbb{D}$, C. Dowson', K. Pickering'2, G. Červinskytè', \\ J. Durham ${ }^{1,2} \mathbb{D}$, N.S. Jakubovics', and R. Holliday ${ }^{1,2} \mathbb{D}$
}

Journal of Dental Research

I-8

(C) International Association for Dental

Research and American Association for Dental, Oral, and Craniofacial Research 2021

\section{(c) (i)}

Article reuse guidelines:

sagepub.com/journals-permissions

DOI: I0.II77/002203452II056287

journals.sagepub.com/home/jdr

\begin{abstract}
Dental procedures produce aerosols that may remain suspended and travel significant distances from the source. Dental aerosols and droplets contain oral microbes, and there is potential for infectious disease transmission and major disruption to dental services during infectious disease outbreaks. One method to control hazardous aerosols often used in industry is local exhaust ventilation (LEV). The aim of this study was to investigate the effect of LEV on aerosols and droplets produced during dental procedures. Experiments were conducted on dental mannequins in an 825.4- $\mathrm{m}^{3}$ open-plan clinic and a $49.3-\mathrm{m}^{3}$ single surgery. Ten-minute crown preparations were performed with an air-turbine handpiece in the open-plan clinic and 10 -min full-mouth ultrasonic scaling in the single surgery. Fluorescein was added to instrument irrigation reservoirs as a tracer. In both settings, optical particle counters (OPCs) were used to measure aerosol particles between 0.3 and $10.0 \mu \mathrm{m}$, and liquid cyclone air samplers were used to capture aerosolized fluorescein tracer. In addition, in the open-plan setting, fluorescein tracer was captured by passive settling onto filter papers in the environment. Tracer was quantified fluorometrically. An LEV device with high-efficiency particulate air filtration and a flow rate of 5,000 L/min was used. LEV reduced aerosol production from the air-turbine handpiece by $90 \%$ within $0.5 \mathrm{~m}$, and this was $99 \%$ for the ultrasonic scaler. OPC particle counts were substantially reduced for both procedures and air-turbine settled droplet detection reduced by $95 \%$ within $0.5 \mathrm{~m}$. The effect of LEV was substantially greater than suction alone for the air-turbine and was similar to the effect of suction for the ultrasonic scaler. LEV reduces aerosol and droplet contamination from dental procedures by at least $90 \%$ in the breathing zone of the operator, and it is therefore a valuable tool to reduce the dispersion of dental aerosols.
\end{abstract}

Keywords: aerosol-generating procedure, dental equipment, infection control, occupational exposure, suction, dental care

\section{Introduction}

Dental procedures produce aerosols and droplets containing oral microbes (Zemouri, Volgenant, et al. 2020; Meethil et al. 2021). This is relevant during infectious disease outbreaks, where concerns over pathogen dissemination (e.g., severe acute respiratory syndrome coronavirus 2) may disrupt dental service provision and pose an infection risk to staff and patients. Pathogen dispersion during aerosol-generating procedures (AGPs) is also an issue in wider health care, for example, during endotracheal intubation (Tran et al. 2012).

The literature relating to airborne disease transmission has been subject to recent scrutiny, and although it is frequently stated that droplets $>5 \mu \mathrm{m}$ diameter do not remain airborne (World Health Organization 2014), this has been questioned by some (Tang et al. 2021). In fact, there is evidence that droplets 60 to $100 \mu \mathrm{m}$ diameter remain suspended, thus posing an inhalation risk (Xie et al. 2007).

Several methods of reducing risks from aerosol dispersion in dentistry have been proposed, for example, reducing aerosol production using alternative dental handpiece designs (Allison, Edwards, et al. 2021; Vernon et al. 2021), reducing pathogenic load with mouthrinses or antimicrobial irrigants, and reducing escape from the mouth using dental dams (SDCEP 2021a). Where potentially contaminated aerosols do escape, ventilation is important in reducing exposure (Zemouri, Awad, et al. 2020), but this is often dictated by building configuration and may be difficult or costly to change. An alternative approach is to use filtration to increase the effective air-exchange rate. This can be achieved using freestanding high-efficiency particulate air (HEPA) filtration devices, but the effect of these is likely to depend on distance from the source and airflow in the room (Ren et al. 2020).

Local exhaust ventilation (LEV) systems are an alternative approach (SDCEP 2021b) and capture aerosols at the source, reducing escape into the environment. LEV is used in industry to protect workers from exposure to dust, fumes, and gases during tasks, including welding and soldering (HSE 2017). These devices have been referred to in the dental literature as

'School of Dental Sciences, Faculty of Medical Sciences, Newcastle University, Newcastle upon Tyne, UK

${ }^{2}$ Newcastle upon Tyne Hospitals NHS Foundation Trust, Newcastle upon Tyne, UK

A supplemental appendix to this article is available online.

\section{Corresponding Author:}

J.R. Allison, School of Dental Sciences, Faculty of Medical Sciences, Newcastle University, Framlington Place, Newcastle upon Tyne, NE2 4BW, UK.

Email: james.allison@newcastle.ac.uk 


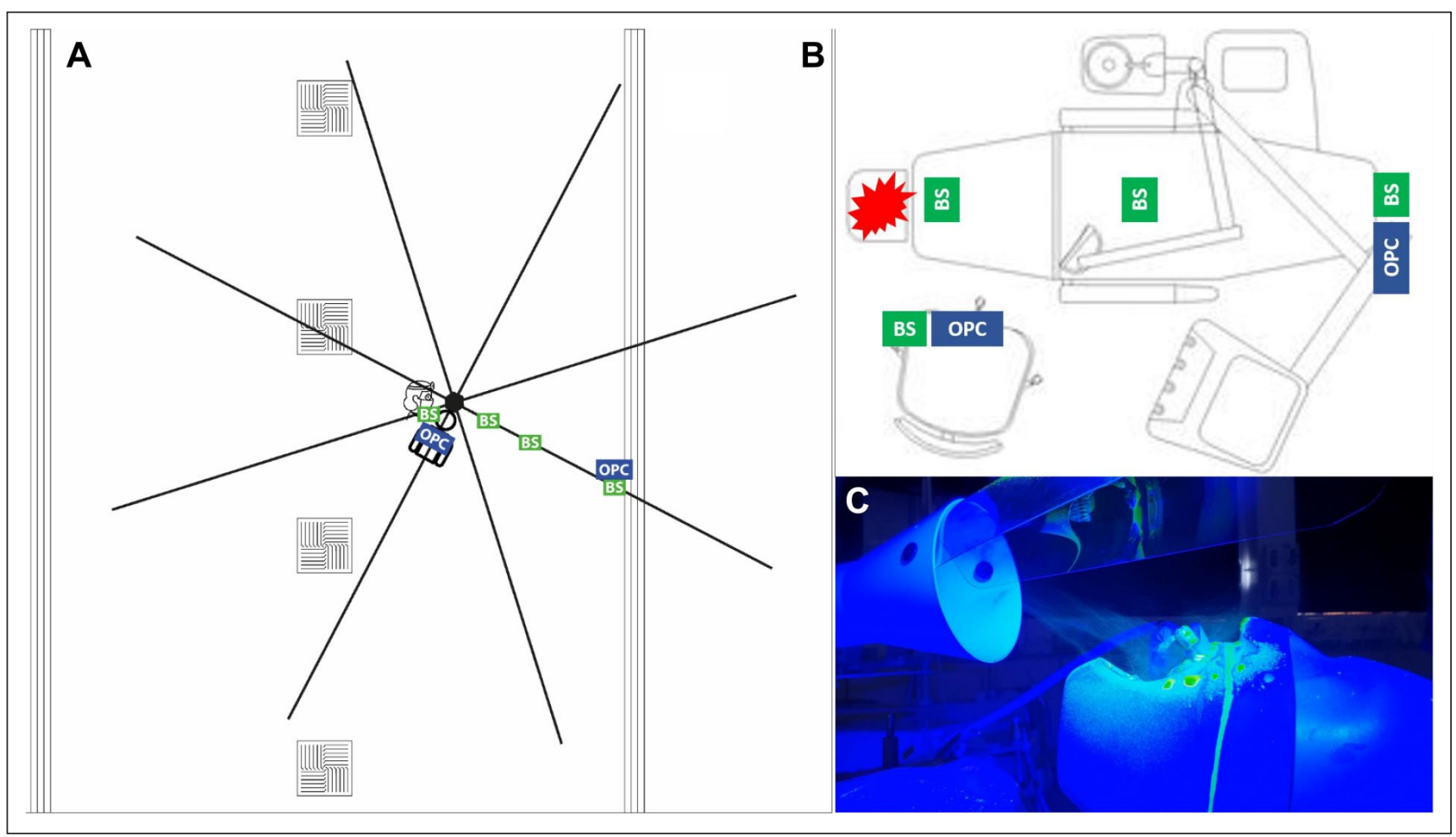

Figure I. Overview of experimental setup. (A) Plan view of open-plan setting. Sampling locations are shown as boxes (BS, BioSampler; OPC, optical particle counter). The position of air vents in the open-plan setting is shown: square vents = air intake; long vents =air output. A rig to support filter papers is shown as black lines radiating from a center above the mannequin. Filter papers were spaced at $0.5-\mathrm{m}$ intervals on each of the 8 rods. (B) Plan view of single-surgery setting as above. The star indicates the location of the aerosol-generating procedure. (C) Positioning of the local exhaust ventilation device in relation to the dental mannequin. Further images are presented in the Appendix.

"extra-oral suction/scavenging," but $L E V$ is a more correct term and is used throughout this article. Previous studies of LEV for dental procedures have reported promising findings, but to our knowledge, none have evaluated both settled droplets and suspended aerosols together (Shahdad et al. 2020; Ehtezazi et al. 2021). While many dental settings constitute enclosed, single operatories, a proportion of care is delivered in large, open-plan clinics, often in educational institutions. The ability of LEV to control the dispersion of aerosols across a large clinical area, thereby reducing exposure to individuals at distant sites, is unknown. The aim of this study is to investigate the effect of LEV on the distribution of aerosols and droplets produced during dental procedures.

\section{Materials and Methods}

\section{Setting}

Open-plan setting. Experiments using an air-turbine handpiece were conducted in an $825.4-\mathrm{m}^{3}$ clinical teaching laboratory at the School of Dental Sciences, Newcastle University, United Kingdom, with a supply and extract heating, ventilation, and air conditioning (HVAC) system providing 6.5 air changes per hour (ACH; assessed by an external engineering contractor) via ceiling vents. Each air exchange reduces contaminants by around $63 \%$; therefore, after 6 air changes, $99.7 \%$ of airborne contaminants will be removed, assuming emission has ceased (SDCEP 2021b). A rig was constructed around a dental mannequin as previously described (Allison, Currie, et al. 2021) comprising platforms spaced at $0.5-\mathrm{m}$ intervals along eight 4-m rods at $45^{\circ}$ intervals supported by a central hub (Fig. 1). This created an $8-\mathrm{m}$ diameter circle around the mannequin, with a center $28 \mathrm{~cm}$ superior to the mannequin's mouth and $73 \mathrm{~cm}$ above the floor. All windows and doors remained closed, and only the operator and assistant were present inside the experimental area, leaving immediately after completing the procedure. We used the air-turbine handpiece in the open-plan setting as our previous data suggest that this instrument produces widespread contamination, which may not be represented in a single surgery setting, compared to the ultrasonic scaler (Allison, Currie, et al. 2021).

Single-surgery setting. Experiments using an ultrasonic scaler were conducted in a $49.3-\mathrm{m}^{3}$ enclosed dental surgery at Newcastle Dental Hospital, Newcastle upon Tyne Hospitals NHS Foundation Trust, United Kingdom. This setting had a supply and extract HVAC system providing 5.0 ACH via ceiling vents. Only the operator and assistant were present inside the experimental area and left immediately after completing the procedure. 


\section{Pilot Testing}

Preliminary experiments undertaken to confirm fluorescein is captured by LEV are described in the Appendix.

\section{Dental Procedures}

Air-turbine handpiece. In the open-plan setting, experiments were conducted on a dental simulator unit (Model 4820; A-dec) with a mannequin containing model teeth (Frasaco $\mathrm{GmbH}$ ). The mouth of the mannequin was positioned $83 \mathrm{~cm}$ above the floor. One operator (RH, height: $170 \mathrm{~cm}$ ) completed an anterior crown preparation of the upper right central incisor for $10 \mathrm{~min}$ using an air-turbine handpiece (Synea TA-98; W\&H (UK) Ltd.). The coolant flow rate was $29.3 \mathrm{~mL} / \mathrm{min}$, and $2.65 \mathrm{mM}$ fluorescein sodium tracer was introduced into the irrigation reservoir of the dental unit. In all experiments in this setting, an assistant operated dental suction with an $8.3-\mathrm{mm}$ internal diameter suction tip at a flow rate of $133 \mathrm{~L} / \mathrm{min}$ of air measured using a flow meter (Ramvac Flowcheck; DentalEZ); this equates to "medium-volume suction" according to UK guidelines (NHS Estates 2003). Three replicates were conducted for each experiment as well as for a negative control condition in which no procedure was occurring.

Ultrasonic scaler. In the single-surgery setting, a dental mannequin (P-6/3 TSE; Frasaco GmbH) was attached to a dental chair (Pelton and Crane Spirit Series) with the mouth positioned $90 \mathrm{~cm}$ above the floor. One of 2 operators $(\mathrm{RH}$, height: $170 \mathrm{~cm}$; GČ, height: $169 \mathrm{~cm}$ ) completed full-mouth ultrasonic scaling for $10 \mathrm{~min}$ using a magnetostrictive scaler (Cavitron Select SPS, 30K FSI-1000-94 insert; Dentsply Sirona) at full power (coolant flow rate: $38.6 \mathrm{~mL} / \mathrm{min}$ ). Fluorescein tracer was used as described above. In some experiments, an assistant operated dental suction with a $14.0-\mathrm{mm}$ internal diameter suction tip at a flow rate of $251 \mathrm{~L} / \mathrm{min}$ of air; this equates to "highvolume suction" (NHS Estates 2003). Three replicates were conducted for each experiment as well as for a negative control condition.

\section{Local Exhaust Ventilation}

A DentalAIR UVC AGP Filtration system (DA-UVC1001; VODEX Ltd.) was used as the LEV device. This device uses a HEPA filter compliant with EN1822 standards at an airflow rate of $5,000 \mathrm{~L} / \mathrm{min}$ of air and includes a $254-\mathrm{nm}, 27-\mathrm{mW} / \mathrm{cm}^{2}$ UVC source in the airflow before filtration. The center of the device's inlet nozzle was positioned $10 \mathrm{~cm}$ inferior to the chin of the mannequin and $4 \mathrm{~cm}$ above the plane of the mannequin's mouth (Fig. 1 and Appendix).

\section{Aerosol and Droplet Detection}

Optical particle counters. In both settings, 2 laser-diode optical particle counters (OPCs; 3016 IAQ; Lighthouse) were used to measure suspended aerosols. OPCs had 6 particle-size channels
$(0.3,0.5,1.0,2.5,5.0$, and $10.0 \mu \mathrm{m})$ with a sampling flow rate of $2.83 \mathrm{~L} / \mathrm{min}$ and were calibrated by the manufacturer to ISO 21501-4. Instruments sampled continuously at 5-s intervals beginning $2 \mathrm{~min}$ before the procedure, continuing during the 10 -min procedure, and for $20 \mathrm{~min}$ after $(32 \mathrm{~min}$ total). OPCs were placed in 2 positions during each experiment (Fig. 1 and Appendix). In the open-plan setting, this was $0.5 \mathrm{~m}$ inferior to the mouth of the mannequin and to the left of the mannequin at $2 \mathrm{~m}$; in the single-surgery setting, this was $0.5 \mathrm{~m}$ to the right of the mannequin and at $2 \mathrm{~m}$ at the foot of the dental chair. Both OPCs were positioned with sampling nozzles $87 \mathrm{~cm}$ above the floor. Data were presented as normalized particle counts (particles $/ \mathrm{m}^{3}$ ) over the time course of the experiment, and total particle counts were summed across all particle size channels. As experiments were conducted in real clinical settings, background particle counts were variable. All OPC data were therefore normalized to an internal baseline by subtracting the average counts during the $2 \mathrm{~min}$ before the procedure from all particle counts. These instruments also measured temperature and relative humidity.

Active air sampling. In both settings, liquid cyclone air samplers (BioSampler; SKC, Inc.) were placed in 4 positions during each experiment (Fig. 1 and Appendix) after cleaning by alternating washing with distilled water and $70 \%$ ethanol to eliminate fluorescein carryover. In the open-plan setting, BioSamplers were positioned in the left chest pocket of the operator and at $0.5,1.0$, and $2.0 \mathrm{~m}$ to the left of the mannequin; in the singlesurgery setting, this was at $0.15 \mathrm{~m}$ on the mannequin (chest), $0.5 \mathrm{~m}$ to the right of the mannequin, and at 1.0 and $2.0 \mathrm{~m}$ on the dental chair. Then, $20 \mathrm{~mL}$ of distilled water was added to the sampling vessels before operation. BioSamplers were operated at an airflow rate of $12.5 \mathrm{~L} / \mathrm{min}$ using a sampling pump (BioLite+; SKC, Inc.) and calibrated using a rotameter (SKC, Inc.). Sampling duration was as for OPCs.

Of the sampled solution, $100 \mu \mathrm{L}$ was then added to wells of a black 96-well microtiter plate with a micro-clear bottom (Greiner Bio-One) in triplicate. Fluorescence was measured using a Synergy HT Microplate Reader (Bio-Tek) at an excitation wavelength of $485 \pm 20 \mathrm{~nm}$ and emission wavelength of $528 \pm 20 \mathrm{~nm}$ with the top optical probe. Negative controls were collected and analyzed in the same way. The mean (SD) fluorescence reading from negative controls in the open-plan setting was 25.2 (1.7) relative fluorescence units (RFU), $n=12$. In the single-surgery setting, this was 25.8 (2.8) RFU, $n=12$. These values were subtracted from all data for background correction.

Passive sampling. This method was used only in the open-plan setting for experiments using the air-turbine handpiece. The $30-\mathrm{mm}$ diameter grade 1 cotton-cellulose qualitative filter papers (Whatman) were placed onto platforms on the rig surrounding the mannequin prior to each experiment following cleaning of platforms with $70 \%$ ethanol. Filter papers were collected following experiments with clean tweezers and placed into individual polypropylene bags. Previous work showed 


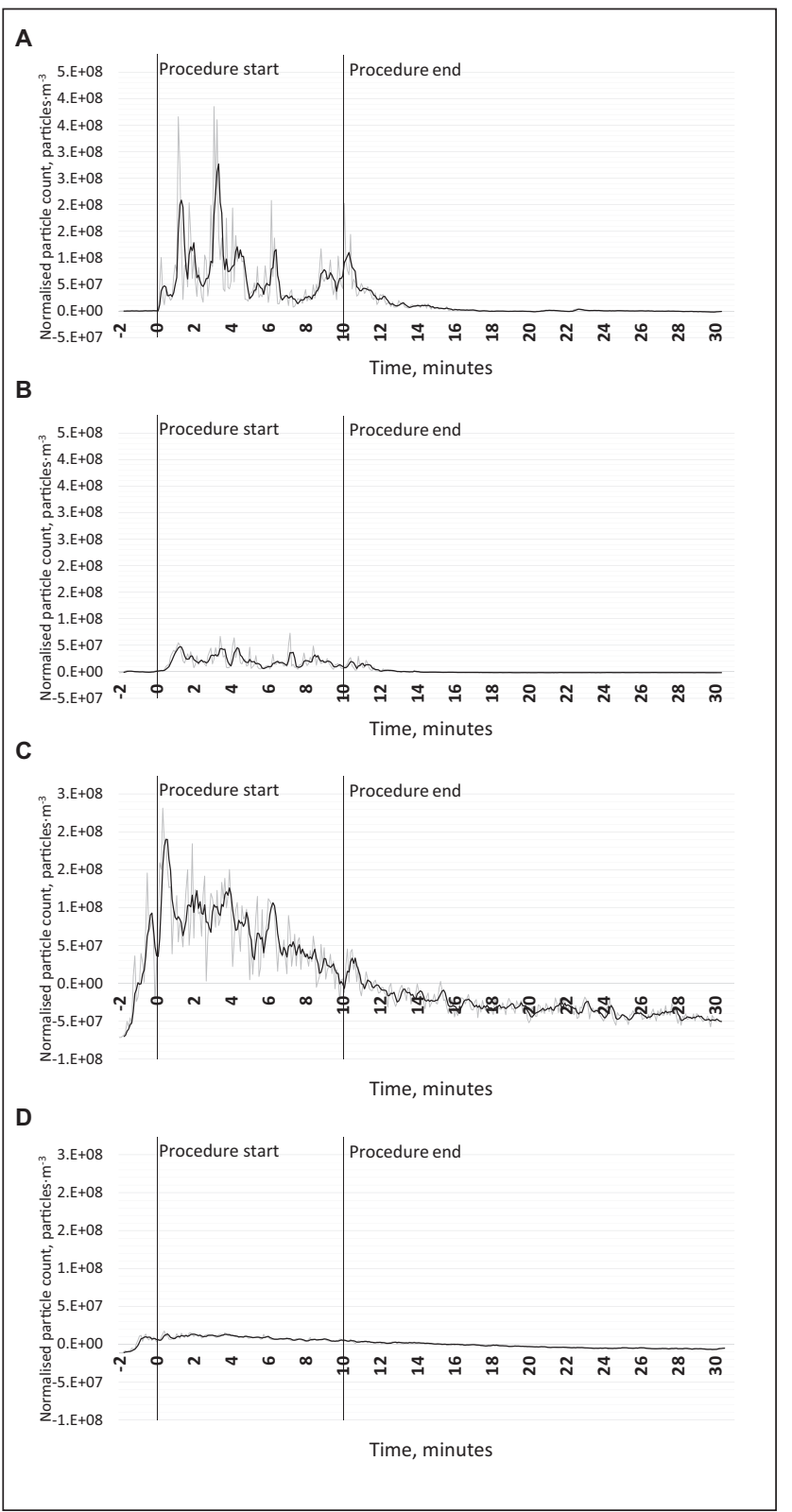

Figure 2. Suspended droplets measured using an optical particle counter at the $0.5-\mathrm{m}$ location. Illustrative data are given in this figure from I repetition of each experiment; data from all repetitions are available in the Appendix, as well as for $2 \mathrm{~m}$ and negative controls. The gray line represents the raw values, and the black line represents a 4-period moving average. (A) Positive control with suction (no local exhaust ventilation [LEV]) using the air-turbine handpiece in the openplan setting. (B) Air-turbine with suction and LEV in the open-plan setting. (C) Positive control (no LEV or suction) using the ultrasonic scaler in the single-surgery setting. (D) Ultrasonic scaler with LEV only in the single-surgery setting.

that this eliminates carryover of fluorescein (Allison, Currie, et al. 2021). Fluorescein was recovered by adding $350 \mu \mathrm{L}$ deionized water. Immersed samples were shaken for $5 \mathrm{~min}$ at $300 \mathrm{rpm}$ using an orbital shaker at room temperature. Fluorescein was eluted by centrifugation at $15,890 \times g$ for 3 min using a microcentrifuge. Then, $100 \mu \mathrm{L}$ of the supernatant was transferred to a black 96-well microtiter plate with a micro-clear bottom (Greiner Bio-One) in triplicate to measure fluorescence using the plate reader as for BioSampler samples.

\section{Statistical Methods}

Data were collected using Excel (2016; Microsoft) and analyzed with SPSS (version 24; SPSS, Inc.) using descriptive statistics.

\section{Results}

Full data sets are available at https://doi.org/10.25405/data .ncl.14987574.

\section{Open-Plan Setting with Air-Turbine Handpiece}

The mean (SD; minimum-maximum) temperature was $23.7^{\circ} \mathrm{C}$ $\left(0.5 ; 22.6-25.1^{\circ} \mathrm{C}\right)$, and the relative humidity was $28.8 \%(6.3$; $20.0 \%-38.6 \%)$.

Active sampling with optical particle counters. OPC data were collected at 2 positions in the open-plan setting: at $0.5 \mathrm{~m}$ to sample aerosols in the breathing zone of the operator and assistant and at $2 \mathrm{~m}$ to sample aerosols at the minimum distance between dental chairs recommended by current UK infection prevention and control guidance (Public Health England 2020). Particle counts were substantially lower during all conditions at $2 \mathrm{~m}$ compared to at $0.5 \mathrm{~m}$. At both $0.5 \mathrm{~m}$ and $2 \mathrm{~m}$, the use of LEV was associated with a substantial reduction in particle counts. Figure 2 shows illustrative data from 1 repetition at $0.5 \mathrm{~m}$. Data from all repetitions, including at $2 \mathrm{~m}$ and negative control, are available in the Appendix.

Active sampling with BioSamplers and fluorometric analysis. Detection of fluorescein decreased with increasing distance from the procedure. The use of LEV was associated with a $75 \%$ to $91 \%$ reduction in aerosolized fluorescein from the airturbine handpiece dependent on location. The percentage reduction decreased with increasing distance from the dental procedure, and this was $90 \%$ within $0.5 \mathrm{~m}$; this distance represents the breathing zone of members of the dental team (Table 1 and Fig. 3).

Passive sampling. Samples were grouped by distance from the procedure: $\leq 0.5 \mathrm{~m}, 1$ to $2 \mathrm{~m}$, and 2.5 to $4 \mathrm{~m}$. Sample RFU values were corrected for background fluorescence by subtracting the mean (SD) background RFU reading from each location $(\leq 0.5 \mathrm{~m}=41$ [20]; $1-2 \mathrm{~m}=41$ [26]; $2.5-4 \mathrm{~m}=39$ [21]) before calculating mean corrected RFU for each location. Values at 1 to $2 \mathrm{~m}$ and 2.5 to $4 \mathrm{~m}$ were substantially lower than at $\leq 0.5 \mathrm{~m}$ (Table 2 and Appendix Fig. 9). At $0.5 \mathrm{~m}$, there was a $95 \%$ reduction in settled fluorescein when LEV was used. Between 1 and $2 \mathrm{~m}$, there was a $69 \%$ reduction, and at 2.5 to $4 \mathrm{~m}$, this was $78 \%$. 
Table I. Aerosolized Fluorescein Collected by BioSampler and Measured Using Fluorometric Analysis.

\begin{tabular}{|c|c|c|c|c|}
\hline Experiment & Position & Mean Fluorescence, RFU & SD & \% Reduction \\
\hline \multicolumn{5}{|c|}{ Air-turbine handpiece: open-plan setting } \\
\hline \multirow[t]{4}{*}{ No LEV (suction), $n=3$} & Operator & 9,878 & 4,478 & Reference \\
\hline & $0.5 \mathrm{~m}$ & $\mathrm{I}, 5 \mathrm{I} 4$ & $\mathrm{I}, 153$ & Reference \\
\hline & $1.0 \mathrm{~m}$ & 581 & 613 & Reference \\
\hline & $2.0 \mathrm{~m}$ & 166 & 116 & Reference \\
\hline \multirow[t]{4}{*}{ LEV and suction, $n=3$} & Operator & 905 & 402 & 90.8 \\
\hline & $0.5 \mathrm{~m}$ & 148 & 39 & 90.2 \\
\hline & $1.0 \mathrm{~m}$ & 99 & 50 & 82.9 \\
\hline & $2.0 \mathrm{~m}$ & 42 & 21 & 74.7 \\
\hline \multicolumn{5}{|c|}{ Ultrasonic scaler: single-surgery setting } \\
\hline \multirow[t]{4}{*}{ No LEV, no suction, $n=3$} & Chest & $\mathrm{I}, 68 \mathrm{I}$ & $\mathrm{I}, 184$ & Reference \\
\hline & $0.5 \mathrm{~m}$ & 560 & 464 & Reference \\
\hline & $1.0 \mathrm{~m}$ & 187 & 68 & Reference \\
\hline & $2.0 \mathrm{~m}$ & 251 & 61 & Reference \\
\hline \multirow[t]{4}{*}{ Suction only, $n=3$} & Chest & 9 & 17 & 99.5 \\
\hline & $0.5 \mathrm{~m}$ & I & 3 & 99.9 \\
\hline & $1.0 \mathrm{~m}$ & 1 & 2 & 99.3 \\
\hline & $2.0 \mathrm{~m}$ & I & 3 & 99.5 \\
\hline \multirow[t]{4}{*}{ LEV only, $n=3$} & Chest & 22 & 41 & 98.7 \\
\hline & $0.5 \mathrm{~m}$ & 1 & 0 & 99.9 \\
\hline & $1.0 \mathrm{~m}$ & 1 & I & 99.7 \\
\hline & $2.0 \mathrm{~m}$ & $0^{\mathrm{a}}$ & 2 & $100.0^{\mathrm{a}}$ \\
\hline \multirow[t]{4}{*}{ LEV and suction, $n=3$} & Chest & 3 & 2 & 99.8 \\
\hline & $0.5 \mathrm{~m}$ & 2 & 2 & 99.6 \\
\hline & $1.0 \mathrm{~m}$ & 2 & I & 98.7 \\
\hline & $2.0 \mathrm{~m}$ & 3 & I & 98.7 \\
\hline
\end{tabular}

Data adjusted for background fluorescence by subtraction of the background reading from all data (open-plan setting: 25.2 relative fluorescence units [RFU], $n=12$; single-surgery setting: 25.8 RFU, $n=12$ ). All air-turbine experiments also used dental suction.

LEV, local exhaust ventilation.

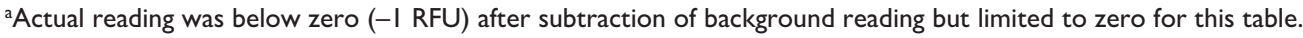

\section{Single-Surgery Setting with Ultrasonic Scaler}

The mean (SD; minimum-maximum) temperature during experiments was $24.1^{\circ} \mathrm{C}\left(0.8^{\circ} ; 22.7^{\circ}-26.4^{\circ} \mathrm{C}\right)$, and relative humidity was $38.5 \%(6.2 \% ; 26.0 \%-45.0 \%)$.

Active sampling with optical particle counters. Particle counts were substantially lower during all conditions at $2 \mathrm{~m}$ compared to $0.5 \mathrm{~m}$. At $0.5 \mathrm{~m}$ and $2 \mathrm{~m}$, the use of LEV was associated with a substantial reduction in particle counts. Figure 2 shows illustrative data from 1 repetition at $0.5 \mathrm{~m}$. Data from all repetitions, including $2 \mathrm{~m}$ and negative control, are available in the Appendix.

Active sampling with BioSamplers and fluorometric analysis. Detection of aerosolized fluorescein decreased with increasing distance from the procedure (Table 1 and Fig. 3). At all locations, LEV was associated with a $98.7 \%$ to $100.0 \%$ reduction in aerosolized fluorescein.

\section{Discussion}

Overall, 3 complementary sets of data at multiple locations, with different dental procedures across 2 clinical settings, robustly demonstrate that LEV is effective in capturing aerosols and droplets from dental procedures and reducing dispersion. This reduction was most significant closest to the procedure, in the breathing zone of the operator and assistant.

Previous studies have evaluated the effectiveness of LEV in dentistry by studying droplet dispersion using a nonfluorescent tracer (Shahdad et al. 2020) and aerosols using particlecounting instruments alone (Ehtezazi et al. 2021). These studies demonstrate substantial reductions in respective measures with LEV, but the present study is the first to examine the effect of LEV on both settled droplets and suspended aerosols simultaneously and the first to capture suspended aerosols with a tracer specific to dental procedures (i.e., not potentially from another source as when measuring particles only). The positioning of LEV in the above studies was also more distant from the source $(15-20 \mathrm{~cm})$, whereas in the present study, positioning was optimal for aerosol capture $(10 \mathrm{~cm})$. Relative reduction in aerosol was most pronounced for the ultrasonic scaler, and we hypothesize that this is because the ultrasonic device produces particles with less momentum than those forced out under compressed air from the air-turbine; we propose that particles from the scaler are therefore more easily captured, explaining the more marked reduction. 
Table 2. Fluorescein Tracer from the Air-Turbine Handpiece, Collected by Settlement onto Filter Paper Samples in the Open-Plan Setting and Measured Using Fluorometric Analysis.

\begin{tabular}{|c|c|c|c|c|}
\hline Experiment & Position ( $n$ Samples) & Mean Fluorescence, RFU & SD & \% Reduction \\
\hline \multicolumn{5}{|c|}{ Air-turbine handpiece: open-plan setting } \\
\hline \multirow[t]{3}{*}{ No LEV (suction), $n=3$} & $\leq 0.5 \mathrm{~m} \mathrm{(27)}$ & 10,726 & 27,367 & Reference \\
\hline & $\mathrm{I}-2 \mathrm{~m}(72)$ & 164 & 338 & Reference \\
\hline & $2.5-4 \mathrm{~m}(96)$ & 66 & 73 & Reference \\
\hline \multirow[t]{3}{*}{ LEV and suction, $n=3$} & $\leq 0.5 \mathrm{~m}(27)$ & 517 & 1,324 & 95.2 \\
\hline & $\mathrm{I}-2 \mathrm{~m}(72)$ & 51 & 155 & 69.0 \\
\hline & $2.5-4 \mathrm{~m}(96)$ & 14 & 33 & 78.3 \\
\hline
\end{tabular}

Data for each group adjusted for background fluorescence in the respective location by subtraction of mean negative control values from each sample $(\leq 0.5 \mathrm{~m}=4 \mathrm{I} \mathrm{RFU}, \mathrm{I}-2 \mathrm{~m}=4 \mathrm{I} \mathrm{RFU}, 2.5-4 \mathrm{~m}=39 \mathrm{RFU})$ before averaging. All experiments also used dental suction.

LEV, local exhaust ventilation; RFU, relative fluorescence units.

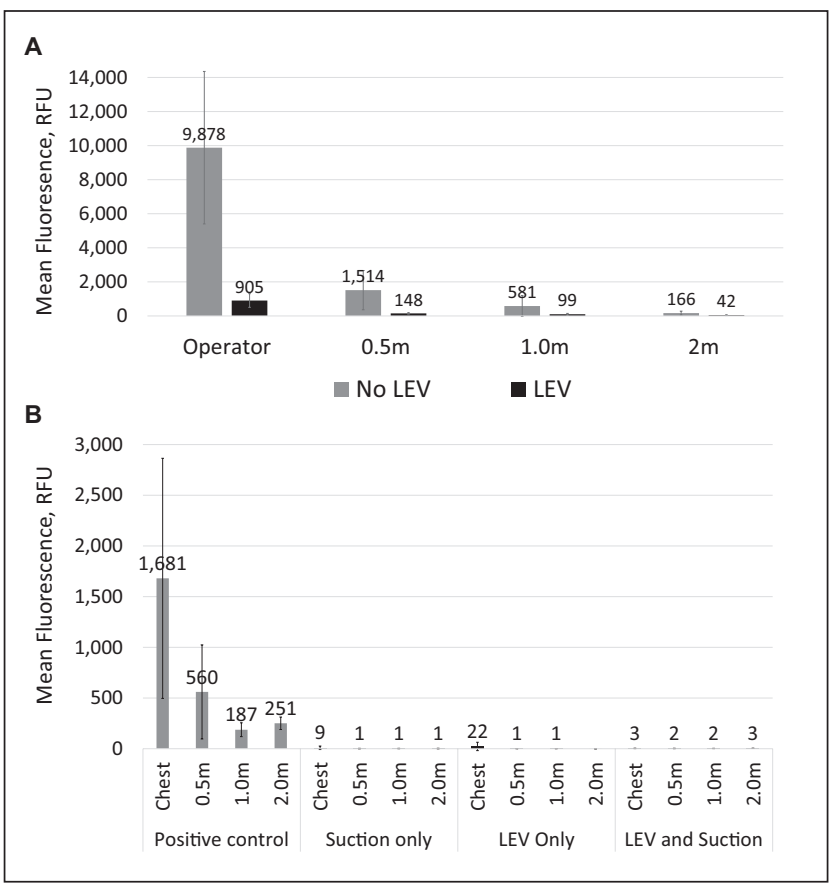

Figure 3. Aerosolized fluorescein collected by BioSampler and measured using fluorometric analysis. Error bars show I SD in each direction. (A) Experiments using the air-turbine handpiece in the open-plan setting (all with suction). Data adjusted for background fluorescence by subtraction of the background reading (25.2 relative fluorescence units [RFU]; $n=12$ ) from all data. (B) Experiments using the ultrasonic scaler in the single-surgery setting. Data adjusted for background fluorescence by subtraction of the background reading (25.8 RFU; $n=12$ ) from all data. LEV, local exhaust ventilation.

We assessed the effectiveness of LEV for aerosol containment during dental procedures and used dental suction during experiments to simulate standard practice. Previous studies demonstrate the significant benefit of dental suction (Allison, Currie, et al. 2021; Holliday et al. 2021), and the present study clearly demonstrates the additional benefit of LEV. In experiments with the air-turbine handpiece, dental suction was used during the control condition and with LEV, and the effect of LEV was marked even in addition to the effect of suction. With the ultrasonic scaler, the effect of suction was also measured separately from LEV, and here the effect of LEV with suction was similar to the effect of LEV alone; however, it was difficult to measure the effect of LEV in addition to suction due to how substantial the effect of suction was alone, with the scaler. This supports the hypothesis that particles from an ultrasonic scaler are more easily controlled with suction and LEV than those from an air-turbine. Importantly, the effect of dental suction may vary depending on the performance of each individual dental vacuum system and the actions of the operator; this is not the case for LEV. In addition, pathogens are captured by the device's HEPA filter, which is usually not the case for dental suction.

This study did not assess the practicality of using LEV for routine dentistry or the acceptability of the device for patients; however, in the authors' opinion, the device is unobtrusive, and there are unlikely to be significant barriers to use other than the floor space required and the need for decontamination. However, buying a device incurs initial costs and recurring costs for increased energy consumption, consumables, and the safe disposal thereof. This is particularly relevant in multichair settings where several devices may be required.

The present study was conducted using a dental mannequin, and patients' respiratory activities, which are significant aerosol sources (Wilson et al. 2021), were therefore not modeled. However, the study aimed to understand the effect of the LEV on the additional aerosols produced by the dental procedure, over and above normal clinical contact - an experimental design using a mannequin is ideal to allow this. The tracer showed where any aerosols from dental instruments were distributed to and the effect of LEV on these. Clearly, it is not the instrument aerosols themselves that pose a risk of infection but the pathogens from saliva carried within these aerosols. Our previous work has shown that "saliva," modeled with a fluorescein tracer, is dispersed by aerosols from dental instruments (Holliday et al. 2021; Llandro et al. 2021). We chose to measure the aerosols from instruments themselves as dispersed "saliva" is likely to be highly diluted; the model used in the present investigation therefore allowed us to demonstrate the effect of LEV with greater sensitivity than if a "saliva"-based model were used. The use of a fluorescent tracer is a reasonably straightforward approach to examine the distribution of dental aerosols, but the biological characteristics of bioaerosols cannot be examined, such as the 
infectivity of dispersed pathogens. Future studies should use biological tracers to validate findings from nonbiological models such as those in the present study.

Particle counts from 0.3- to $10-\mu \mathrm{m}$ OPC channels were combined, as this provides an easily comparable measure across experiments and is consistent with measures used in airquality monitoring combining particles $<10 \mu \mathrm{m}$, for example, $\mathrm{PM}_{10}$ (although this uses particle mass instead of number as in the present study). It is likely that particles of differing size behave differently; however, it was not the aim of the present study to examine this.

\section{Conclusion}

This study demonstrates that LEV reduces aerosols from dental procedures by at least $90 \%$ within $0.5 \mathrm{~m}$. While no mitigation measure alone will completely eliminate risk, LEV appears to be a useful approach, which, in addition to other measures, substantially reduces dispersion of aerosols and therefore risk of exposure to pathogens. LEV seems more effective at capturing aerosols from ultrasonic scalers with less energetic droplets, compared to with an air-turbine handpiece, but the effect remained substantial for the latter. LEV therefore shows promise in reducing aerosols from dental procedures and should play a role in reducing risks from dental bioaerosols.

\section{Author Contributions}

J.R. Allison, R. Holliday, contributed to conception, design, data acquisition, analysis, and interpretation, drafted and critically revised the manuscript; C. Dowson, contributed to design, data acquisition, and analysis, critically revised the manuscript; K. Pickering, G. Červinskyte, contributed to design and data acquisition, critically revised the manuscript; J. Durham, N.S. Jakubovics, contributed to conception, design, and data interpretation, critically revised the manuscript. All authors gave final approval and agree to be accountable for all aspects of the work.

\section{Acknowledgments}

We thank Philippa McClen for her support with this work.

\section{Declaration of Conflicting Interests}

The authors declared the following potential conflicts of interest with respect to the research, authorship, and/or publication of this article: This work was commissioned and funded by VODEX Ltd., Southampton, UK. The research was undertaken by independent investigators at the School of Dental Sciences, Newcastle University. VODEX Ltd. did not have any input into the design or conduct of this study or the content of the manuscript. J.R. Allison, J. Durham, N.S. Jakubovics, and R. Holliday have received related grants from the British Endodontic Society and the Royal College of Surgeons of Edinburgh, which did not fund the present work. C. Dowson is funded by a National Institute of Health Research (NIHR) Newcastle Biomedical Research Centre Studentship. The views expressed are those of the authors and not necessarily those of VODEX Ltd., the National Health Service, NIHR, or the Department of Health and Social Care.

\section{Funding}

The authors disclosed receipt of the following financial support for the research, authorship, and/or publication of this article: Financial support was received for this study from VODEX Ltd.

\section{ORCID iDs}

\author{
J.R. Allison (iD https://orcid.org/0000-0002-0562-4133 \\ J. Durham (iD https://orcid.org/0000-0002-5968-1969 \\ R. Holliday iD https://orcid.org/0000-0002-9072-8083
}

\section{References}

Allison JR, Currie CC, Edwards DC, Bowes C, Coulter J, Pickering K, Kozhevnikova E, Durham J, Nile CJ, Jakubovics N, et al. 2021. Evaluating aerosol and splatter following dental procedures: addressing new challenges for oral healthcare and rehabilitation. J Oral Rehab. 48(1):61-72.

Allison JR, Edwards D, Bowes C, Pickering K, Dowson C, Stone SJ, Lumb J, Durham J, Jakubovics N, Holliday R. 2021. The effect of high-speed dental handpiece coolant delivery and design on aerosol and droplet production. J Dent. 112:103746.

Ehtezazi T, Evans DG, Jenkinson ID, Evans PA, Vadgama VJ, Vadgama J, Jarad F, Grey N, Chilcott RP. 2021. SARS-CoV-2: characterisation and mitigation of risks associated with aerosol generating procedures in dental practices Br Dent J [epub ahead of print 7 Jan 2021]. doi:10.1038/s41415-020-2504-8

Holliday R, Allison J, Currie C, Edwards D, Bowes C, Pickering K, Reay S, Durham J, Lumb J, Rostami N, et al. 2021. Evaluating contaminated dental aerosol and splatter in an open plan clinic environment: implications for the COVID-19 pandemic. J Dent. 105:103565.

HSE. 2017. Controlling airborne contaminants at work: a guide to local exhaust ventilation (LEV) (HSG258). London: The Stationary Office [accessed 2021 Dec 10]. https://compositesuk.co.uk/system/files/healthsafety/documents/Controlling\%20airborne $\% 20$ contaminants $\% 20$ at $\% 20$ work $\% 20$ -\%20a\%20guide $\% 20$ to $\% 20$ LEV.pdf

Llandro H, Allison J, Currie C, Edwards D, Bowes C, Durham J, Jakubovics N, Rostami N, Holliday R. 2021. Evaluating splatter and settled aerosol during orthodontic debonding: implications for the COVID-19 pandemic. Br Dent $\mathrm{J}$ [epub ahead of print 8 Jan 2021]. doi:10.1038/s41415-020-2503-9

Meethil AP, Saraswat S, Chaudhary PP, Dabdoub SM, Kumar PS. 2021 Sources of SARS-CoV-2 and other microorganisms in dental aerosols. J Dent Res. 100(8):817-823.

NHS Estates. 2003. HTM 2022-supplement 1: dental compressed air and vacuum systems. London: The Stationary Office.

Public Health England. 2020. COVID-19: infection prevention and control dental appendix. London: Public Health England [accessed 2021 Dec 10]. https://www. gov.uk/government/publications/wuhan-novel-coronavirus-infection-preven tion-and-control/covid-19-infection-prevention-and-control-dental-appendix.

Ren Y, Huang Q, Marzouk T, Richard R, Pembroke K, Martone P, Venner T, Malmstrom H, Eliav E. 2020. Effects of mechanical ventilation and portable air cleaner on aerosol removal from dental treatment rooms. J Dent. 105:103576.

SDCEP. 2021a. Mitigation of aerosol generating procedures in dentistry: a rapid review (version 1.2) [accessed 2021 Sep 14]. https://www.sdcep.org.uk/ wp-content/uploads/2021/04/SDCEP-Mitigation-of-AGPs-in-DentistryRapid-Review-v1.2-April-2021.pdf.

SDCEP. 2021b. Ventilation information for dentistry [accessed 2021 Sep 14]. https://www.sdcep.org.uk/wp-content/uploads/2021/05/SDCEP-VentilationInformation-for-Dentistry.pdf.

Shahdad S, Patel T, Hindocha A, Cagney N, Mueller J-D, Seoudi N, Morgan C, Din A. 2020. The efficacy of an extraoral scavenging device on reduction of splatter contamination during dental aerosol generating procedures: an exploratory study. Br Dent J [epub ahead of print 11 Sep 2020]. doi:10.1038/s41415-020-2112-7

Tang JW, Bahnfleth WP, Bluyssen PM, Buonanno G, Jimenez JL, Kurnitski J, Li Y, Miller S, Sekhar C, Morawska L, et al. 2021. Dismantling myths on the airborne transmission of severe acute respiratory syndrome coronavirus (SARS-CoV-2). J Hosp Infect. 110:89-96.

Tran K, Cimon K, Severn M, Pessoa-Silva CL, Conly J. 2012. Aerosol generating procedures and risk of transmission of acute respiratory infections to healthcare workers: a systematic review. PLoS One. 7(4):e35797.

Vernon JJ, Black EVI, Dennis T, Devine DA, Fletcher L, Wood DJ, Nattress BR. 2021. Dental mitigation strategies to reduce aerosolization of SARSCoV-2. J Dent Res [epub ahead of print 2 Aug 2021]. doi:10.1177/ 00220345211032885 
World Health Organization. 2014. Infection prevention and control of epidemicand pandemic-prone acute respiratory infections in healthcare-WHO guidelines [accessed 2020 Nov 25]. https://www.who.int/publications/i/ item/infection-prevention-and-control-of-epidemic-and-pandemic-proneacute-respiratory-infections-in-health-care.

Wilson NM, Marks GB, Eckhardt A, Clarke AM, Young FP, Garden FL, Stewart W, Cook TM, Tovey ER. 2021. The effect of respiratory activity, non-invasive respiratory support and facemasks on aerosol generation and its relevance to covid-19. Anaesthesia. 76(11): $1465-1474$.
Xie X, Li Y, Chwang AT, Ho PL, Seto WH. 2007. How far droplets can move in indoor environments-revisiting the wells evaporation-falling curve. Indoor Air. 17(3):211-225.

Zemouri C, Awad SF, Volgenant CMC, Crielaard W, Laheij AMGA, de Soet JJ. 2020. Modeling of the transmission of coronaviruses, measles virus, influenza virus, mycobacterium tuberculosis, and legionella pneumophila in dental clinics. J Dent Res. 99(10):1192-1198.

Zemouri C, Volgenant CMC, Buijs MJ, Crielaard W, Rosema NAM, Brandt BW, Laheij A, De Soet JJ. 2020. Dental aerosols: microbial composition and spatial distribution. J Oral Microbiol. 12(1):1762040. 